\title{
What factors can influence children's perception of forests today and in the future?
}

\author{
Thiago Braz Barbosa de Sousa ${ }^{1}$ Taline Cristina da Silva ${ }^{2 *}$ and \\ Marcelo Alves Ramos ${ }^{3}$
}

\begin{abstract}
Ethnobiological studies regarding the environmental perception of children are still infrequent, creating a gap in the understanding of factors that influence the process of developing perception in this phase of life. Therefore, this study sought to verify the influence of some factors, such as contact with natural environments, gender, and age in elementary school students, between 11 and 15 years of age, about remnants of the Atlantic Forest, present and future. We observed that the elements represented by children did not differ in terms of contact with natural environments, but those who live in rural areas, represented more elements related to usefulness. Additionally, the children in this study did not show significant differences in environmental representations between genders, and an increase in age indicated the loss of ecological knowledge about the natural components of a forest environment, giving way to a more utilitarian and degraded view of the environment. In general, we can state that children have precise perceptions about forest environments, and a negative perspective regarding the future of forests. Furthermore, certain factors may come to have a strong influence on their perception, especially with increasing age and strengthening of culturally established social roles for different genders, which will strongly influence decision-making in favor of forests in the future.
\end{abstract}

Keywords: Ethnobiology; Environmental Representation; Students Perception.

1 Programa de Pós-Graduação em Ciência e Tecnologia Ambiental, Universidade de Pernambuco, Nazaré da Mata - PE, 55800-000, Brazil

2 Universidade Estadual de Alagoas (UNEAL), Campus III, Rod. Eduardo Alves da Silva, Km 3 - Graciliano Ramos, Palmeira dos Índios-AL, Brazil- CEP: 57604-595.

3 Laboratório de Estudos Etnobiológicos, Universidade de Pernambuco, Campus Mata Norte, Nazaré da Mata - PE, 55800-000, Brazil

* Corresponding author $\bowtie$. E-mail address: TBBS (brazeadu@gmail.com), TCS (talinecs@hotmail.com)*, MAR(marcelo.alves@upe.br)

\section{SIGNIFICANCE STATEMENT}

Some factors tend to influence the adult environmental perception. With children, we could see that these factors were not always strong determinants. Contact with natural environments through visits has not been shown to influence children's environmental representations, but rather the environment in which they live. Children do not yet have well-defined social roles, and increasing age has been shown to reduce the ecological knowledge of natural components. Schools actively participate in building children's perceptions and knowledge, and this environment can lead to attitudes in favor of the environment, avoiding the future destruction of these environments. 


\section{INTRODUCTION}

Environmental perception is a cognitive process that corresponds to how each individual perceives their external world, how they observe phenomena, and attribute concepts to them. It reflects a set of psychological, physiological, social, and cultural filters (Rocha et al. 2006; Silva et al. 2016a; Tuan 1980).

Studies on environmental perception are mainly focused on diagnosing and understanding environmental problems from the adult's point of view (see Almeida et al. 2016; Barbosa et al. 2020; Durán López et al. 2016; Kohler et al. 2015; Silva et al. 2016; Westling et al. 2014). Only a small number of studies are focused on children and adolescents (see Bento-Silva et al. 2015; Pellier et al. 2014; Silva et al. 2010), despite the importance of investigating the perception of the natural environment at this stage in life, especially since it is common to develop perceptions aimed at contemplating nature among young people, and individual values and attitudes begin developing at this stage (Silva et al. 2010; Tuan 1980).

Considering environmental perception as a sociocultural phenomenon, ethnobiological studies carried out with adults indicate that perception can be influenced by several factors, such as increased contact with natural environments, gender, and age (see Silva et al. 2016a). Thus, it is plausible to speculate that these factors may also modulate the perceptions of children and adolescents. For example, if there is a greater amount of forest fragments in rural areas, it is expected that children and adolescents living in that region will be able to have more contact with nature, explore it intensively, and develop more affective connections and other cognitive processes with these environments. On the other hand, those who live in urban areas, which generally have fewer natural environments, have less access to and interactions with nature (Çubukçu et al. 2018; Zhang et al. 2014).

The greatest contact with natural environments can occur regardless of where individuals live. For example, there are activities, such as educational and contemplative visits, that contribute to developing knowledge and affective connections with these environments, as well as the development of biophilia (Bowker 2007; Burgess and Mayer-Smith 2011). Thus, when we say that contact with natural environments influences children's perceptions, we need to consider the region where children and adolescents live and the opportunities to interact with nature that they experience during their life (Almeida et al. 2016; Quinlan et al. 2016; Silva et al. 2016).

Gender also influences the environmental perception of individuals, since in most societies there is a strong division in social roles between men and women, which can alter the construction of knowledge through different lived experiences (Silva et al. 2016b; Torrez-Avilez et al. 2016). In southern Brazil, for example, women from a rural community often limit themselves to exploring environments close to home, such as backyards, gardens, and orchards, while men explore native forest environments (Poderoso et al. 2017), which results differences in knowledge about natural resources based on gender. In many societies these distinct social roles linked to gender can begin during childhood (Gallois et al. 2015). For example, in some cultures hunting is a common activity for males, which contributes to increased knowledge of bird species compared to females (Pam et al. 2018; Setapalaphruk and Price 2007). According to Zhang et al. (2014) girls can develop a greater fear of animals when compared to boys because their exploration of the environment can be spatially limited, which impacts the development of knowledge and perceptions.

It is common for individuals of different ages to have different environmental perceptions, since this can be associated with cognitive and psychological development, as well as with perceived cultural meaning. Children can move from a phase of contemplating nature in childhood to a utilitarian perception in adolescence, considering what nature can offer for their material survival (Silva et al. 2010). Moreover, with increasing age there is a greater understanding of complex issues and knowledge about certain subjects (Oliveira et al. 2019).

Therefore, understanding the environmental perceptions of the younger public is essential to planning environmental intervention measures, in addition to understanding the vision of these social actors in future environmental conservation challenges. Studies have shown that children and adolescents are able to perceive the consequences of possible long-term changes in natural environments, such as species extinction, loss of resources, and climate change due to deforestation (Pellier et al. 2014). For this reason, it is important to understand the perceptions and knowledge of younger demographics about the forest environment in the present and future, in order to contribute to planning measures aimed at the educational processes, and to discuss other forms of intervention that sensitize these generations to environmental causes. Few environmental perception studies have been conducted in the Brazilian Atlantic Forest with children and adolescents (Bento-Silva et al. 2015; Schwarz et al. 2007; Silva et al. 2010), and there is a lack of studies analyzing youth perspectives regarding the future of these environments. In the contemporary scenario, with intense environmental degradation that consequently affects human health and quality of life, it is important to involve everyone in order to minimize this situation, especially younger gener- 
ations, who will be responsible for making decisions in the future (Pellier et al. 2014; Dickel and Bonnin 2019).

In the following study, we seek to investigate the environmental perceptions of children and adolescents about Atlantic Forest remnants through their representations in the present and future, as well as the factors that may come to influence them. We seek to answer the following questions:

a) Are there changes in forest representations for children and adolescents in relation to the present and the future? (exploratory question)

b) Does contact with natural environments influence the number of elements represented by children and adolescents? We expect that those who live in rural areas and/or had opportunities to visit natural environments, represent more forest elements.

c) Does gender influence the number of elements represented by children and adolescents? Boys are expected to represent more forest elements.

d) Does age influence the number of elements represented by children and adolescents? Those who are older are expected to represent more forest elements.

\section{MATERIAL AND METHODS}

\section{Studied area}

This research was conducted in the phytogeographic domain of the Atlantic Forest, in the city of Carpina, state of Pernambuco, Northeast Brazil (Figure 1). The Atlantic Forest is considered one of the most biodiverse and threatened areas on the planet, and provides essential services for the population, such as water supply, climate regulation, agriculture, fishing, electricity, and tourism. In addition, about $72 \%$ of the Brazilian population, and the three largest urban centers on the South American continent are located in this area (SOS Mata Atlântica and INPE 2020). In terms of access to natural environments, only $12.6 \%$ of the original cover of the Atlantic forest remains in the state of Pernambuco, a direct result of urbanization, implantation of industries, livestock, and agriculture (with emphasis on sugarcane monoculture) (Dean 1996; SOS Mata Atlântica and INPE 2020). Around only $3 \%$ of forest remnants remain in the city of Carpina,

For this study, we selected elementary school students from a public school. The city has an area of $147,665 \mathrm{Km}^{2}$ with an estimated population of 81,884 inhabitants and an urbanization rate of 95.60\% (IBGE 2016). Its school network has 56 elementary and middle schools, 12 high schools, and
46 pre-schools. The chosen school is classified as difficult to access, although it is in an urban area, and the students who participated in the research reside both in the city of Carpina and in surrounding cities. The school offers both middle school and high school classes, with approximately 675 students enrolled from the 6 th to the 9 th grade of middle school and 10th to 12 th grade of high school.

The school is located in a woodland environment, and during the observation period and data collection many classes took place in open spaces, outside the classroom, due to insufficient classroom space for the number of enrolled students, as well as poor ventilation within the buildings. Although some classes are external, no field classes have been reported in the woodland areas close to the school. The school runs a project called "Fiscal and Environmental Education," and although it does not have Environmental Education as a curricular component, it develops this approach in an interdisciplinary manner. The teachers, along with the administration, stated that they had taken a field trip with the students in the previous year to the Pernambuco' Botanical Garden, located in Recife, the capital of the state.

\section{Data collection}

We made initial visits to the school to explain the nature and objectives of the research, as well as to present the Informed Consent Form (TCLE) to the administration, staff, and teachers. After the authorization to conduct the study was given, a class from each grade, between the 6th and 9th grade, was identified and selected. We invited the students to participate in the research on a voluntary basis. A total of 135 students agreed to participate from the 358 enrolled in the selected grades.

Data collection was carried out in three stages and applied concurrently. During the first stage, the students were invited to produce an essay based on the stimulus: "What do you think about the forest near the region where you live?" (Barraza and Ceja-Adame 2003). On this occasion, through a semi-structured questionnaire, we also asked students to answer some socioeconomic questions, such as age, gender, location (urban or rural area), and if they had already visited any forests (Table 1). Students were also asked to indicate the sources of information where they obtained knowledge about forests.

In a second step, based on Pellier et al. (2014), we invited students to make drawings based on the stimuli: "What do you see in the forest near the region where you live?" In a third instance, students were invited to create another drawing from the stimulus: "What do you expect to see in this forest in the future?" These stimuli were used to register the 


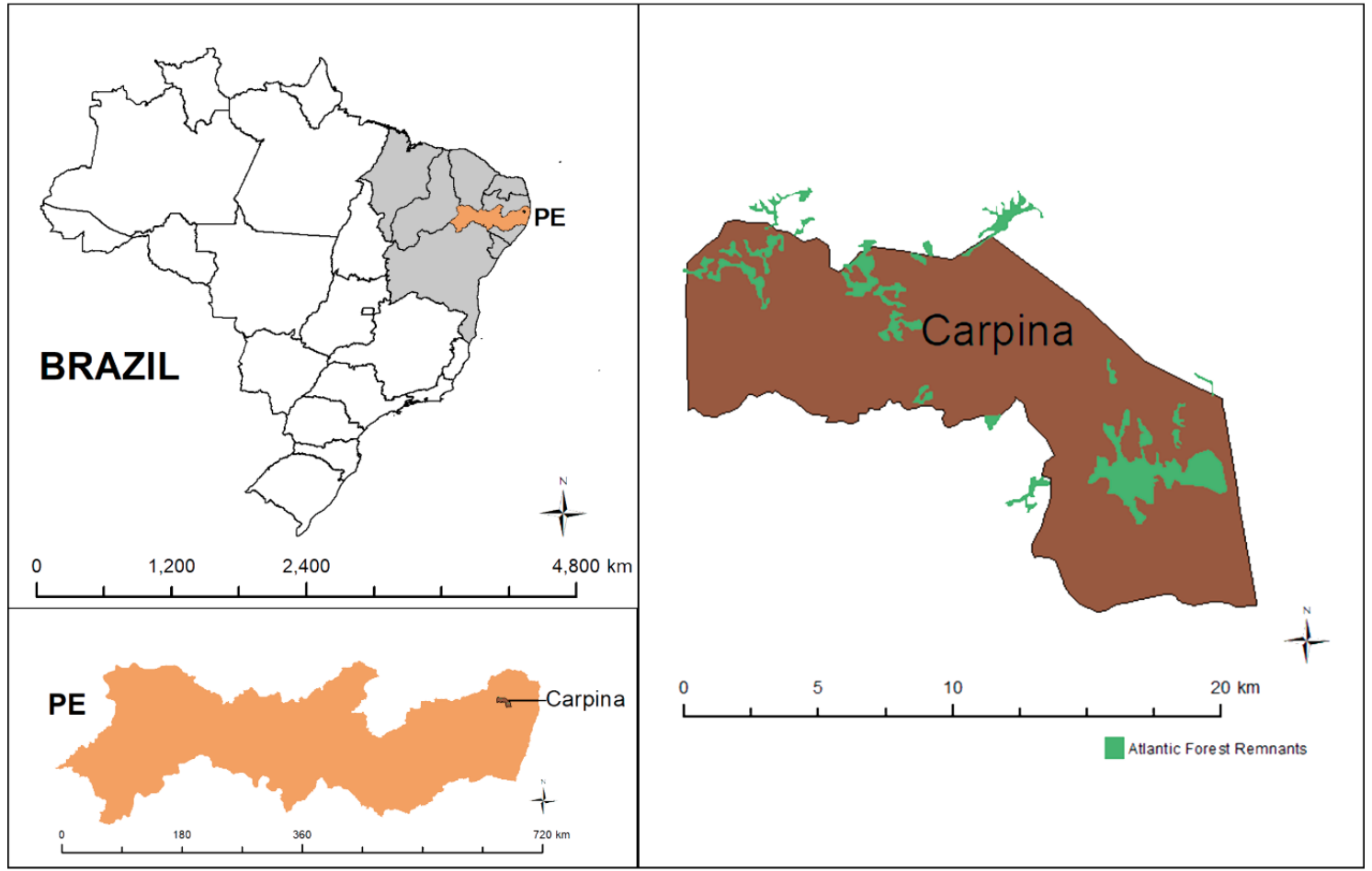

Figure 1. Localization of Carpina - PE, Northeast of Brazil, with their forest remnants according with SOS Mata Atlântica and INPE data base.

Table 1. Socioeconomic data of the research participants.

\begin{tabular}{lll}
\hline \hline Categories & & \% Interviewees (n) \\
\hline \hline \multirow{2}{*}{ Gender } & a) Female & $53.3(72)$ \\
& b) Male & $46.3(63)$ \\
\hline \multirow{2}{*}{ Geographical area } & a) Rural & $10.3(14)$ \\
& b) Urban & $89.6(121)$ \\
\hline \multirow{2}{*}{ Visited the forest? } & a) Visited the forest & $55.5(75)$ \\
& b) Did not visit the forest & $44.4(60)$ \\
\hline \multirow{5}{*}{ Age } & a) 11 & $34.0(46)$ \\
& b) 12 & $25.9(35)$ \\
& c) 13 & $14.8(20)$ \\
& d) 14 & $14.8(20)$ \\
e) 15 & $10.3(14)$ \\
\hline \hline
\end{tabular}

Source: The author

perceived components, the types of relationships students establish with forests, and what they hope for the future of this natural environment. During the last two stages, we asked students to identify the elements represented, in order to have a more precise analysis later. We provided materials for the drawings and essays, such as A4 sheets of paper, graphite, colored pencils, erasers, and sharpeners.

The two methods of data collection (drawing and writing) were necessary for methodological triangulation, so students had the opportunity to express their perceptions in different ways, since they could have a limitation in one of the methods used (Silva et al. 2010).

\section{Ethics Aspects}

This research is part of the project: "Forest resources in the Pernambuco forest zone: potential for use and conservation priorities," which was submitted to and approved by the Ethics Committee of the University of Pernambuco (CAAE: 19938013.1.0000.5207). In order to initiate the research, parents of underage students were asked to 
sign the Informed Consent to allow their child's participation in the study (Resolution 510/2016 of the National Health Council).

\section{Data Analysis}

After data collection, we analyzed the essays and drawings, grouping each element according to the categories from Barraza and Ceja-Adame (2003) adapted by Silva et al. (2010), outlined in Table 2. The elements that did not fall into the defined categories and those with a low frequency of occurrence were classified as "other." For example, elements linked to fiction, such as Pokémon and Iron Man; elements linked to culture and religion, such as folk legends and angels; terms that cover general concepts such as photosynthesis, ecosystem, etc.

\section{Statistical analysis}

For the drawing analysis, in present and future representations, we carried out a Kruskal-Wallis test, considering the aforementioned variables and a significant result when $p<0.05$. In this test, we only compare the number of elements drawn between students in the two-time frames (present and future) and involve other independent variables separately because it was our exploratory question.

We define an accumulation curve in relation to the quantity of words in the texts written by students both in urban areas and rural areas, indicating a stabilization of the elements in both groups. We first used a generalized linear model (GLM) with a Gaussian distribution to analyze which factors explain the total number of elements represented in the students' essays. The total number of words was sqrttransformed to achieve normality. Then, the number of each type of wording element (biotic, abiotic, adjective, anthropic, degraded and utilitarian) was relativized by the total number of elements written in each student's essay. Next, we performed a GLM with a Gaussian distribution for each type of wording. Since we had undesired effects of a high proportion of zeros for most models, we conducted two models for each response variable with high proportion of zeros (all variables except "biotic"): a) a GLM with a binomial distribution and a logit link function where the response variable was whether the student wrote at least one word (1) or did not write any word (1) from the wording; and b) a GLM with a Gaussian distribution where the response variable was the relative number of focal type words and only considered those students that wrote at least one focal type word. In models b), response variables were sqrt or arcsin (sqrt) transformed to achieve normality and homoscedasticity of model residuals.
In all models we used the following explanatory variables: Visited the forest (factor), Location (factor), Gender (factor), and Age (ordered factor).

\section{RESULTS AND DISCUSSION}

\section{Representations of the Atlantic rainfor- est in the present and the future in the children's drawings}

Through the drawings, a total of 4,765 elements were represented. Of this total, 2,859 (60\%) elements were from the landscape in the present and 1,906 $(40 \%)$ were elements for forests in the future.

In the present, the most represented elements are in the biotic $(56.3 \%)$, utilitarian $(23.8 \%)$, and abiotic $(17.3 \%)$ categories, while the anthropic (1.6\%) and degradation $(0.52 \%)$ categories were underrepresented in this time frame. In future projections, there was an emphasis on biotic (30.6\%), anthropic (26.9\%), abiotic (18.7\%), and degradation $(16.3 \%)$ categories, and the utilitarian category $(7.6 \%)$ was the least expressive. In general, this alteration in landscape by time frame presented a statistically significant variation $(\mathrm{H}=25.6452 ; p<0.0001)$, indicating that in the students' perspective, a considerable increase in the incidence of anthropic elements and degradation in natural environments will occur in the future, with humans being represented most of the time as a degrading agent.

The human figure is represented through machines and tools, which symbolize the removal and cutting of trees, as well as in the presence of buildings, roads, automobiles, and industries, together with the pollution of rivers and air. Figure 2 shows the representations of some students in relation to the current and future state of the forest.

When the drawings were analyzed according to location, we found that students residing in rural areas represented, on average, more elements in the utilitarian category in the present than those living in urban areas, this result was statistically significant $(\mathrm{H}=5.3598 ; p=0.0206)$. The other categories for drawings were equivalent for this variable (Table 3 ).

For drawings and time frames, no significant differences were found for the variable "Visited the forest" between the analyzed categories. In terms of gender, we could see that male students had a greater number of anthropic elements in the present period than female students $(\mathrm{H}=7.2145 ; p=0.0072)$. The other categories did not show significant differences for this variable in the drawings (Table 4).

In the present time drawings, the "biotic" category stood out in terms of the age of the students, and was increasingly represented by 11-year-old students compared to 13 -year-old students $(\mathrm{H}=3.9317$; $\mathrm{p}=$ 
Table 2. Analysis Categories for elements from essays and drawings made by students about the forest (Barraza and Ceja-Adame 2003; Silva et al. 2010).

\begin{tabular}{|c|c|c|}
\hline Categories & Description & Elements \\
\hline Abiotic & $\begin{array}{l}\text { Includes elements related to physical } \\
\text { and chemical factors of the environ- } \\
\text { ment, which are not capable of the } \\
\text { life characteristics of adaptability, re- } \\
\text { producibility. }\end{array}$ & $\begin{array}{l}\text { Water, soil, air, sky, cloud, sun, rocks } \\
\text { and waterfalls }\end{array}$ \\
\hline Adjective (only for texts) & $\begin{array}{l}\text { Are included words that qualify the for- } \\
\text { est }\end{array}$ & beautiful, ugly, large, deforested, etc. \\
\hline Anthropic & $\begin{array}{l}\text { Covers elements resulting from human } \\
\text { action }\end{array}$ & houses, buildings, fences, roads, etc. \\
\hline Biotic & $\begin{array}{l}\text { Includes elements related to or belong- } \\
\text { ing to living organisms and organic } \\
\text { components of the biosphere }\end{array}$ & $\begin{array}{l}\text { trees, plants, plantations, grass, fruits } \\
\text { (in morphological aspects presented in } \\
\text { texts), flower, root, leaves, etc. }\end{array}$ \\
\hline Degradation & $\begin{array}{l}\text { Contains elements that represent dam- } \\
\text { age to the environment, causing the } \\
\text { loss of biodiversity, its productivity and } \\
\text { quality }\end{array}$ & $\begin{array}{l}\text { deforestation, burning, pollution, } \\
\text { garbage, etc. }\end{array}$ \\
\hline Utilitarian & $\begin{array}{l}\text { Includes elements of the forest that } \\
\text { have utility or interest as their main } \\
\text { purpose }\end{array}$ & $\begin{array}{l}\text { fruits (as a food to be collected), wood, } \\
\text { fresh air, and medicines }\end{array}$ \\
\hline
\end{tabular}
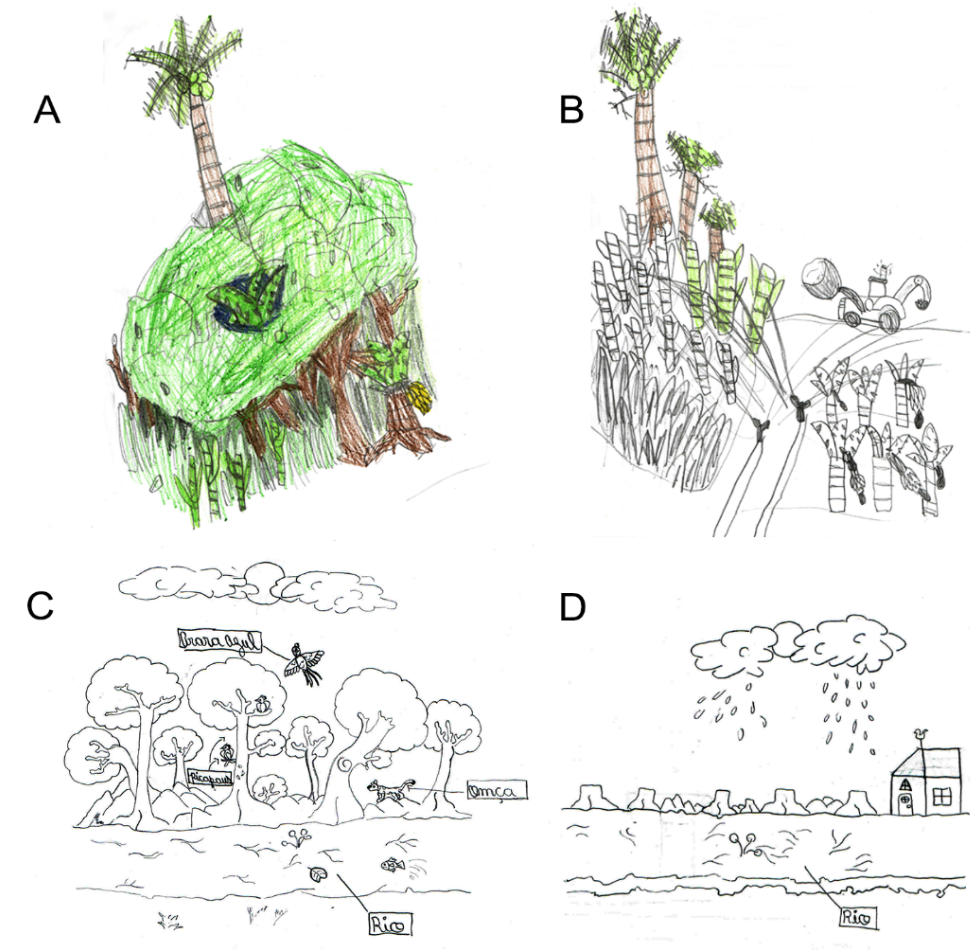

Figure 2. Representations from elementary school students about the forest in the region where they live. (A, $\mathrm{C})=\operatorname{present} ;(\mathrm{B}, \mathrm{D})=$ future.

$0.0474)$ and 15-year-old students $(\mathrm{H}=4.4915 ; \mathrm{p}=$ 0.034). Likewise, 12-year-old students tended to represent a greater number of elements in this category than 15-year-old students $(\mathrm{H}=3.9039 ; p=0.0482)$, as can be seen in Table 5 .

In regard to age and the future of forests, we ob- 
Table 3. Average elements represented through drawings by students in the present and future, according to location.

\begin{tabular}{lllll}
\hline \hline \multirow{2}{*}{ Categories } & \multicolumn{2}{c}{ Present } & \multicolumn{2}{c}{ Future } \\
& Rural & Urban & Rural & Urban \\
\hline \hline Abiotic & $3.75^{a}$ & $3.66^{a}$ & $2.12^{a}$ & $2.70^{a}$ \\
Anthropic & $0.5^{a}$ & $0.40^{a}$ & $3.1^{a}$ & $3.89^{a}$ \\
Biotic & $13.37^{a}$ & $11.69^{a}$ & $4.31^{a}$ & $4.32^{a}$ \\
Degradation & $0.06^{a}$ & $0.12^{a}$ & $1.68^{a}$ & $2.39^{a}$ \\
Utilitarian & $9.31 \mathrm{a}$ & $\mathbf{4 . 4 8}^{b}$ & $2.25^{a}$ & $0.90^{a}$ \\
\hline \hline
\end{tabular}

Different letters on the same line and bold text indicate significant differences using the Kruskal-Wallis test $(p<0.05)$.

Table 4. Average elements represented through drawings by students in the present and future, according to gender.

\begin{tabular}{lllll}
\hline \hline \multirow{2}{*}{ Categories } & \multicolumn{2}{c}{ Present } & \multicolumn{2}{c}{ Future } \\
& Female & Male & Female & Male \\
\hline \hline Abiotic & $3.62^{a}$ & $3.73^{a}$ & $3.0^{a}$ & $2.18^{a}$ \\
Anthropic & $0.20^{a}$ & $\mathbf{0 . 6 8}^{b}$ & $3.29^{a}$ & $4.41^{a}$ \\
Biotic & $12.5^{a}$ & $11.12^{a}$ & $5.4^{a}$ & $2.98^{a}$ \\
Degradation & $0.08^{a}$ & $0.15^{a}$ & $2.45^{a}$ & $2.11^{a}$ \\
Utilitarian & $4.46^{a}$ & $5.78^{a}$ & $1.10^{a}$ & $1.0^{a}$ \\
\hline \hline
\end{tabular}

Different letters on the same line and bold text indicate significant differences using the Kruskal-Wallis test $(p<0.05)$

Table 5. Average of elements represented through drawings by students in the present, according to age.

\begin{tabular}{llllll}
\hline \hline \multirow{2}{*}{ Categories } & \multicolumn{5}{c}{ Present } \\
\cline { 2 - 6 } & $\mathbf{1 1}$ & $\mathbf{1 2}$ & $\mathbf{1 3}$ & $\mathbf{1 4}$ & $\mathbf{1 5}$ \\
\hline \hline Abiotic & $3.28^{a}$ & $4.30^{a}$ & $3.38^{a}$ & $3.18^{a}$ & $3.06^{a}$ \\
Anthropic & $0.28^{a}$ & $0.44^{a}$ & $0.33^{a}$ & $0.54^{a}$ & $0.5^{a}$ \\
Biotic & $12.74^{a}$ & $\mathbf{1 4 . 4 1}^{a c}$ & $\mathbf{8 . 5 2}^{b}$ & $9.04^{a}$ & $\mathbf{7 . 6 5}^{b d}$ \\
Degradation & $0.065^{a}$ & $0.11^{a}$ & $0.14^{a}$ & $0.09^{a}$ & $0.19^{a}$ \\
Utilitarian & $5.79^{a}$ & $3.94^{a}$ & $5.28^{a}$ & $4.86^{a}$ & $3.5^{a}$ \\
\hline \hline
\end{tabular}

Different letters on the same line and bold text indicate significant differences using the Kruskal-Wallis test $(p<0.05)$.

served that there was a significant difference between 11 and 12 years old students in relation to the anthropic category, where older students represented the forest in an anthropized manner $(\mathrm{H}=6.8073$; $\mathrm{p}=$ 0.0091). However, for future forests, 11-year-old students represent a scenario with fewer elements in the "degradation" category than 12-year-old students (H $=6.7946 ; p=0.0096$ ) (Table 6).

The influence of contact with natural environments, gender, and age on children's forest representations through essays
The interviewed students represented a total of 1,100 elements through the essays, with the majority in the biotic (54\%), degradation (12.4\%), and abiotic $(11.9 \%)$ categories (Figure 3$)$. In general, we observed that the students who answered "have not visited the forest" mentioned a greater variety of elements than the others in their essays $(\mathrm{R}=4.99 ; p=0.025$; Table 7 ), indicating that our hypothesis was not corroborated. Thus, considering the total number of elements mentioned, the variables "location" was not significant $(\mathrm{R}=3.29 ; p=0.069)$, neither was gender $(\mathrm{R}=0.13$; 
Table 6. Average elements represented through drawings by students in the future, according to age.

\begin{tabular}{llcccc}
\hline \hline \multirow{2}{*}{ Categories } & \multicolumn{5}{c}{ Future } \\
\cline { 2 - 6 } & $\mathbf{1 1}$ & $\mathbf{1 2}$ & $\mathbf{1 3}$ & $\mathbf{1 4}$ & $\mathbf{1 5}$ \\
\hline \hline Abiotic & $2.26^{a}$ & $3.22^{a}$ & $2.71^{a}$ & $2.47^{a}$ & $1.69^{a}$ \\
Anthropic & $4.24^{a}$ & $\mathbf{2 . 3 8}^{b}$ & $5.28^{a}$ & $2.68^{a}$ & $3.81^{a}$ \\
Biotic & $4.32^{a}$ & $4.97^{a}$ & $3.14^{a}$ & $3.09^{a}$ & $4.5^{a}$ \\
Degradation & $1.0^{a}$ & $\mathbf{3 . 5 5}^{b}$ & $1.76^{a}$ & $3.81^{a}$ & $1.0^{a}$ \\
Utilitarian & $1.71^{a}$ & $1.08^{a}$ & $0.33^{a}$ & $0.45^{a}$ & $0.5^{a}$ \\
\hline \hline
\end{tabular}

Different letters on the same line and bold text indicate significant differences using the Kruskal-Wallis test $(p<0.05)$.

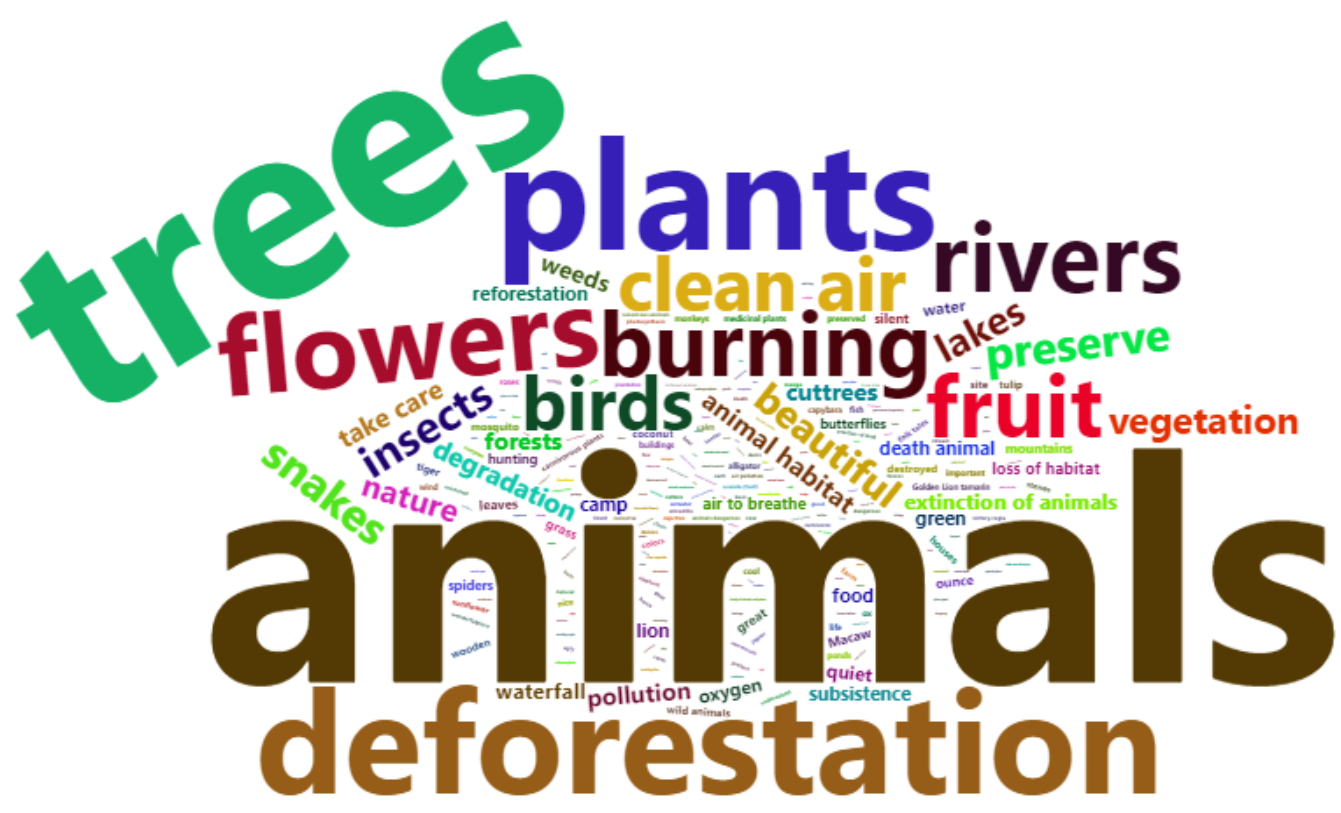

Figure 3. The most frequent words mentioned by the children in the essays using the stimulus "What do you think about the forest near the region where you live?".

$p=0.713)$ or age $(\mathrm{R}=7.22 ; p=0.124)$, as can be seen in Table 7.

\section{DISCUSSION}

The children's representations of the forest degradation process were intense, especially in the future time frame. Children are continuously building their worldview, which are conceptualized experiences (Tuan 1980). They can develop negative perspectives on future conditions of natural environments, which may be associated with the consequences of growing up in a world of constant warnings about the environment, resource depletion, and the need for nature conservation (Profice 2018). These warnings may be based on mass media, which students pointed out as one of the main sources of information about the forest they represented, as previously mentioned. The formal and informal teaching and learning model can also shape perceptions about current and future environmental conditions (Pellier et al. 2014), and consequently, children may develop the perception that humans and their actions in nature are a threat to biodiversity.

Although the children studied by Pellier et al. (2014) were all from rural areas, they also perceived the human figure as the cause of environmental degradation, with the reduction and loss of biodiversity as a future consequence. Children, as well as adults, are able to understand that the environmental degra- 
Table 7. Results of the GLM analysis of students' essays on the forest, relating socioeconomic variables and the number of words cited.

\begin{tabular}{llcccc}
\hline \hline \multirow{2}{*}{ Independent variables } & & $\begin{array}{c}\text { Essays } \\
\text { Forest Visited }\end{array}$ & Age & Gender & Location \\
\hline \hline \multirow{2}{*}{ Total } & $\chi^{2}$ & 4.99 & 7.22 & 0.13 & 3.29 \\
& $\mathrm{P}$ & $\mathbf{0 . 0 2 5}$ & 0.124 & 0.713 & 0.069 \\
\hline \multirow{2}{*}{ Biotic } & $\chi^{2}$ & 0.36 & 22.61 & 0.63 & 0.13 \\
& $\mathrm{P}$ & 0.545 & $\mathbf{0 . 0 0 1}$ & 0.426 & 0.713 \\
\hline \multirow{2}{*}{ Abiotic } & $\chi^{2}$ & 0.34 & 5.91 & 0.00 & 0.54 \\
& $\mathrm{P}$ & 0.559 & 0.205 & 0.962 & 0.458 \\
\hline \multirow{2}{*}{ Adjective } & $\chi^{2}$ & 0.00 & 3.46 & 0.55 & 0.49 \\
& $\mathrm{P}$ & 0.985 & 0.483 & 0.456 & 0.480 \\
\hline \multirow{2}{*}{ Anthropic } & $\chi^{2}$ & 0.48 & 8.93 & 1.49 & 0.81 \\
& $\mathrm{P}$ & 0.484 & 0.062 & 0.221 & 0.367 \\
\multirow{2}{*}{ Degradation } & $\chi^{2}$ & 3.02 & 6.90 & 0.40 & 0.15 \\
& $\mathrm{P}$ & 0.081 & 0.140 & 0.526 & 0.691 \\
\hline \multirow{2}{*}{ Utilitarian } & $\chi^{2}$ & 0.02 & 4.24 & 1.23 & 0.24 \\
& $\mathrm{P}$ & 0.862 & 0.373 & 0.266 & 0.619 \\
\hline Df & & 1 & 4 & 1 & 1 \\
\hline \hline
\end{tabular}

Bold numbers indicate significant differences based on means pairwise comparisons using Tukey's method.

dation is mainly due to human activities such as deforestation, pollution, and illegal forest activities, and these are long-term problems that need attention (Hernandez-Tapia et al. 2018). Thus, our findings contribute to the idea that children have a sophisticated perception of these environments and understand the impacts of human activity on wildlife and other natural resources through changes in the landscape (Pellier et al. 2014; Sousa et al. 2019).

Student's contact with forests through visits did not seem to influence the representations regarding its natural components, and contrary to what was expected, those who had never visited forests demonstrated more knowledge of its components. Burgess and Mayer-Smith (2011) argue that children's perception is often limited to direct experiences and general observations of the natural world, even children who have reduced or nonexistent natural spaces, have developed an idea of nature as a place to play and explore. In addition, modernization and access to information through different media and social networks can favor students' knowledge of forests, regardless of having ever visited a forest (Quinlan and Quinlan 2007). The teaching and learning model can also contribute to the standardization of knowledge, especially if it is not contextualized with each student's reality, that is, students who have been to a forest or not, may have similar knowledge, because they learned from a textbook and content taught in class (Silva et al. 2010; Pellier et al. 2014).

Our results also indicate that children living in rural areas represent forests from a more utilitarian perspective in relation to those in urban areas. In the region, studies indicate that communities in rural areas close to forest fragments are dependent on natural resources, and usually use firewood from forests, in addition to carrying out agricultural activities as a means of subsistence (Arruda et al. 2019). Similarly, with students from another rural area in northeastern Brazil, Silva et al. (2010) found a large number of forest representations associated with different uses. Therefore, the utilitarian forest perception may occur more strongly among those who live in rural areas, since this dependence results in greater resource knowledge (Quinlan et al. 2016). Moreover, dependence on natural resources and children's involvement in these uses, enable them to both understand their environment and connect with nature, as well as observe changes that can occur directly in their environment (Pellier et al. 2014).

There are no differences between genders in regards to forest elements in students' essays, which is explained once again by the two factors previously mentioned in this text: a) access to information from different media (Quinlan and Quinlan 2007) and b) standardization of knowledge based on the teaching and learning model that can be decontextualized with the different student realities (Silva et al. 2010). However, male student's drawings showed a greater number of perceived anthropic elements from the forest environment, demonstrating that gender does not influence the perceptions and knowledge of biodiversity, 
but rather the human effect on the landscape. Children's drawings can represent experiences, desires, feelings, and reality, but they can also reflect cultural and socioeconomic issues (Oğuz 2010; Quaglia et al. 2015). Some studies show differences between the drawings of boys and girls, indicating that girls tend to draw more colorful things than boys, who prefer shades of brown, gray, and black (Peña-larios and Gutiérrez-Barba 2017; Serin 2003). In our study, we found that girls did draw more colorful elements than boys, such as flowers and butterflies. Therefore, this factor can explain boys representing more anthropic elements, like building, roads, and fences, since these figures have less colors.

In this study, we expected that the increase in age would indicate a greater range of citations and representations of forest components; however, we found the opposite of what we expected. Student knowledge on biodiversity was fragmented with advancing age, and with a possible decrease in interest because it represents natural components. However, students demonstrate a better understanding and concern with the phenomenon of degradation as they get older. Children's perceptions of deteriorating environments can be shaped by their school education or by the media. In the latter case, the information is generally negative and focuses on species extinction, deforestation, and environmental disasters (Pellier et al. 2014). Nevertheless, this perception can undergo changes as school years progress, and the student's school environment can shape children's perception during their cognitive development (Bento-Silva et al. 2015). This enables students to understand more complex issues, as well as the development of attitudes that search for a solution to environmental problems. Thus, one way to contribute to the expansion of local environmental issues is through the contextualization of teaching in the educational process, since this can influence the individual development of children (Oliveira et al. 2019) and contribute to future pro-environmental decisions.

\section{FINAL CONSIDERATIONS}

From theoretical point of view, this study advances the understanding of how socioeconomic variables influence the perception processes of younger people about nature. Our results showed that there are no quantitative differences in the representations of young people about the forest, but qualitatively these differed due to socioeconomic variables. For example, we found that rural children represented the forest as useful resource, since they probably use it as a source of subsistence, which is important to preserve for long term use. This finding is important from a practical point of view, as future conservation actions can be targeted more specifically at certain groups. Schools are favorable environments to begin these actions, since they strongly contribute to the social and cultural development of children and young people, serving as a source of information and guiding many of the processes that contribute to the construction of their global visions.

In general, students demonstrated an understanding of the consequences when there is an increase in environmental degradation, such as the reduction of biodiversity and useful natural resources from their daily lives. Although the variable gender did not influence the knowledge of these young people, advancing age indicates changes in the way they perceive these environments. Thus, over the years age may strengthen and differentiate social roles according to the local culture, as well as shape perceptions and values in relation to natural environments, which will directly affect the attitudes and decisions made about the future of these environments.

Lastly, there are some limitations in this study regarding the chosen public and information that was not collected may bias some of our results; therefore, we present some suggestions to avoid them in future studies. The interviewed public, aged between 11 and 15 years old, may have restricted access to forest environments, especially those of the female gender, due to cultural issues. In this case, the frequency of visitation is reduced and can only be with adults. Thus, in addition to the variables tested here, for future studies we also recommend collecting data on whether the regularity (weekly, monthly, annually) in which children visit forest areas influences their perception; and test the variable "restricted access" to forest areas to examine whether it can cause a difference in the perceptions of boys and girls.

\section{ACKNOWLEDGEMENT}

We would like to thank the teachers and managers of the participating school, for all the support and reception during data collection, and Katiane Oliveira for such help during that moment. We would also like to thank Xavier Arnan for his contributions to the statistical analysis, and Emre Suner for review and suggestions. Thank you for the financial support from National Council for Scientific and Technological Development (Conselho Nacional de Desenvolvimento Cientifico e Tecnológico - CNPq) throughout the course of this research. We also thank the University of Pernambuco and the Laboratory of Ethnobiological Studies (LEET). 


\section{DATA AVAILABILITY}

The data used to support the finding of this study are available from the corresponding author upon reasonable request.

\section{CONFLICT OF INTEREST}

The authors have no conflicts of interest to declare.

\section{CONTRIBUTION STATEMENT}

Conceived the idea presented: MAR, TCS

Carried out the study: TBBS

Carried out the data analysis: TBBS, TCS

Wrote the first draft of the manuscript: TBBS, MAR Review and final writing of the manuscript: TBBS, TCS, MAR

Supervision: MAR

\section{REFERENCES}

Almeida GMA, Ramos MA, Araújo EL, Baldauf C, Albuquerque UP (2016) Human perceptions of landscape change: The case of a monodominant forest of Attalea speciosa Mart ex. Spreng (Northeast Brazil). Ambio 45:458-467.

Arruda HLS, Santos JFO, Albuquerque UP, Ramos MA (2019) Influence of Socioeconomic Factors on the Knowledge and Consumption of Firewood in the Atlantic Forest of Northeast Brazil. Economic Botany 73:1-12.

Barbosa EC, Cruz RS, Santos GMC, Silva RRV, Albuquerque UP, Medeiros PM (2020) Use Categories and Local Perception of Decline in Plant Populations: a Case Study of Woody Medicinal Plants in Northeastern Brazil. Economic Botany 74:356-362.

Barraza L, Ceja-Adame MP (2003) Los niños de la comunidade: su conocimiento ambiental y su percepción sobre naturaleza. In: Velázquez A, Torres A, Bocco G (eds) Las enseñanzas de San Juan: Investigación participativa para el manejo integral de recursos naturales. 1st ed. NE-SEMARNAT.

Bento-Silva JS, Andrade WM, Ramos MA, Ferraz EMN, Souto WM, Albuquerque UP, Araújo EL (2015) Students' Perception of Urban and Rural Environmental Protection Areas in Pernambuco, Brazil. Tropical Conservation Science 8:813-827.

Bowker R (2007) Children's perceptions and learning about tropical rainforests: an anal- ysis of their drawings. Environmental Education Research 13:75-96.

Çubukçu E, Kahraman DE, Yavaşal ÖF (2018) Comparing the lifestyles and environmental perceptions of rural and urban children: a case study in Turkey. Journal of Housing and the Built Environment 33:861-875.

Dean W (1996) A ferro e fogo: a história de devastação da Mata Atlântica brasileira. Companhia das Letras, São Paulo.

Dickel VJ, Bonnin JJ (2019) Study of the environmental ecological environment: perception of children and young people of the schools from Obligado District, Department of Itapúa. Revista Agrogeoambiental doi: 10.18406/2316-1817v11n320191326.

Durán López ME, Barrientos Llosa Z, Charpentier Esquivel C (2016) Environmental perception by urban school children: influence of green areas, financing and sex in Costa Rica. UNED Research Journal 8:31-39.

Gallois S, Duda R, Hewlett B, Reyes-García V (2015) Children's daily activities and knowledge acquisition: A case study among the Baka from southeastern Cameroon. Journal of Ethnobiology and Ethnomedicine 11:1-13.

Hernández-Tapia R, Valverde T, Aranda A, MartínezPeralta C, Platas-Neri D (2018) Traditional knowledge as a basis for the development of a sustainable resource management program: A case study in a rural village in Morelos, Mexico. Ethnobiology Letters 9:1-11.

Kohler F, Marchand G, Negrão M (2015) Local history and landscape dynamics: A comparative study in rural Brazil and rural France. Land Use Policy 43:149-160.

Oliveira JV, Lopes SF, Barboza RRD, Trovão DMMB, Ramos MB, Alves RRN (2019) Wild vertebrates and their representation by urban/rural students in a region of northeast Brazil. Journal of Ethnobiology and Ethnomedicine 15:1-23.

Pam G, Zeitlyn D, Gosler A (2018) Ethnoornithology of the mushere of Nigeria: Children's knowledge and perceptons of birds. Ethnobiology Letters 9:48-64.

Pellier AS, Wells JA, Abram NK, Gaveau D, Meijaard E (2014) Through the eyes of children: Perceptions of environmental change in tropical forests. PLOS ONE 9: e103005.

Poderoso RA, Peroni N, Hanazaki N (2017) Gender Influences in the Perception and Use of 
the Landscape in a Rural Community of German Immigrant Descendants in Brazil. Journal of Ethnobiology 37:779-797.

Profice C (2018) Nature as a living presence: Drawings by Tupinambá and New York Children. PLOS ONE 13:1-15.

Quinlan MB, Quinlan RJ (2007) Modernization and Medicinal Plant Knowledge in a Caribbean Horticultural Village. Medical Anthropology Quarterly 21:169-192.

Quinlan MB, Quinlan RJ, Council SK, Roulette JW (2016) Children's Acquisition of Ethnobotanical Knowledge in a Caribbean Horticultural Village. Journal of Ethnobiology 36:433-456.

Rocha CFD, Bergallo HG, Sluys MV, Alves MAS (2006) Biologia da Conservação: essências. RiMa Editora.

Serin Y (2003) Figure, color, size and content relations in children's picture. Inönü University Faculty of Education Journal 4:85-98.

Setalaphruk C, Price LL (2007) Children's traditional ecological knowledge of wild food resources: A case study in a rural village in Northeast Thailand. Journal of Ethnobiology and Ethnomedicine 3:1-11.

Silva TC, Chaves AG, Albuquerque UP (2016a) What is environmental perception? In: Albuquerque UP, Alves RRN (eds) Introduction to Ethnobiology. 1st ed. Springer International Publishing, pp. 93-98.

Silva TC da, Campos LZO, Silva JS, Sousa RS, Albuquerque UP (2016b) Biota Perception and Use. In: Albuquerque UP, Alves RRN (eds) Introduction to Ethnobiology. 1st ed. Springer International Publishing, pp. 99-104.

Silva TC, Medeiros PM, Araújo TAS, Albuquerque UP (2010) Northeastern Brazilian students' rep- resentations of Atlantic Forest fragments. Environment, Development and Sustainability 12:195-211.

Silva TC, Ramos MA, Schwarz ML, Alvarez IA, Kill LHP, Albuquerque UP (2014) Local representations of change and conservation of the riparian forests along the São Francisco River (Northeast Brazil). Forest Policy and Economics 45:1-12.

Sousa TBB, Silva TC, Ramos MA (2019) A representação ambiental de estudantes da zona da mata Norte de Pernambuco sobre a Floresta Atlântica. In: Seabra G (ed) Terra - Políticas Públicas e Cidadania. Barlavento, Ituiutaba, MG, pp. 1565-1577.

Torres-Avilez WM, Nascimento ALB do, Campos LZO, Silva FS, Albuquerque UP (2016) Gender and Age. In: Albuquerque UP, Alves RRN (eds) Introduction to Ethnobiology. Springer International Publishing, pp. 239-244.

Tuan YF (1980) Topofilia: um estudo da percepção, atitudes e valores do meio ambiente. 1st ed. DIFIEL, São Paulo.

Westling EL, Surridge BWJ, Sharp L, Lerner DN (2014) Making sense of landscape change: Long-term perceptions among local residents following river restoration. Journal of Hydrology 519:2613-2623.

Zhang W, Goodale E, Chen J (2014) How contact with nature affects children's biophilia, biophobia and conservation attitude in China. Biological Conservation 177:109-116.

Received: 13 November 2020

Accepted: 02 February 2021

Published: 12 April 2021 